\title{
Availability of Vocational Training and Additional Vocational Education for Citizens at the Retirement Age in Russia and Abroad
}

\author{
Lyudmila Voronina \\ Ural Federal University named after B.N. Yeltsin \\ Yekaterinburg, Russian Federation \\ e-mail: voronina_612@outlook.com
}

\author{
Tatyana Rezer \\ Ural Federal University named after B.N. Yeltsin \\ Yekaterinburg, Russian Federation \\ e-mail: t.m.rezer@urfu.ru
}

\begin{abstract}
The authors of the article have analyzed how the availability of vocational training and additional vocational education for citizens at the retirement age in Russia and abroad is ensured. The purpose is to analyze the conditions of the organization of training for elderly citizens in Russia and abroad. The system research method has allowed one to analyze the organization of training for this category of citizens and to identify the conditions under which the availability of vocational training and additional professional education in Russia and abroad is possible on the basis of adopted laws and stateestablished guarantees. The authors conclude that different countries use legal, organizational and social mechanisms for public management of educational services for citizens at the retirement age. Despite the differences in economy and culture, many countries share a common understanding of the possibilities of citizens at the retirement age, as well as the understanding that different conditions, including educational ones, must be created for people at this age.
\end{abstract}

Keywords - citizens at the retirement age; mechanisms of public administration; vocational training; additional professional education; access to education for citizens at the retirement age.

\section{INTRODUCTION}

The relevance of the research is determined by the global trends in creating conditions for the education of elderly citizens. At the Fifth International Conference on Adult Education, held in Hamburg in 1997, adult education was identified as a key focus in the XXI century. The participants of the conference recommended that all governments of the world would consider adult education, which integral part is the education of older citizens, as one of the priorities of state policy [1]. In accordance with this recommendation, many countries have adopted and are implementing the concept of continuing education, in which the number of the adult population up to $80 \%$ should be covered by various forms of education. In Russia the adult education rate is $30 \%$, and among citizens at the retirement age it is equal to $0.1 \%$ (for comparison: there are $36 \%$ of citizens at the retirement age trained in Germany) [2]. In modern Russia, as in many other countries, there is an understanding that in public administration it is necessary to create mechanisms and conditions for citizens at the retirement age to receive educational services of public sphere, as well as services for vocational training and obtaining additional vocational education in such forms as seminars, refresher courses and training, internships. Through such services citizens of this age group are able to continue their active social life and work. In this case, the society and the economy of the country can receive qualified workers who live a full and harmonious life.

\section{Methodology OF THE RESEARCH}

The system approach makes it possible to explain the way of development and functioning of any system. The use of this method becomes possible when the research is faced with the task of explaining the integrative properties of an object that is not the result of a simple summation of parts, and whose properties cannot be identified through the features of its constituent elements. Within the framework of our research the system method, focused on the application of the principle of integrity and intersystem interaction, allows us to identify the conditions under which the availability of vocational training and additional vocational education for citizens at the retirement age in Russia and abroad would become real. The comparative legal method allows us to analyze the legislation and strategies on which the organization of adult education in Russia and abroad is based.

\section{THE RESEARCH RESULTS}

The authors of the study have come to several conclusions. The concept of "availability of vocational training and additional vocational education for citizens at the retirement age in Russia and abroad" is a very complex one. The use of comparative analysis allows us to identify the conditions for ensuring the availability of training for elderly citizens:

1. The existence of laws and other regulatory legal acts that establish and implement the right to get educational services by citizens of this category, including funding from the state budget, the funds of employers, which costs are partly compensated by the state.

2. Information about educational services available to elderly citizens, it is presented on the official websites of educational organizations, employment centers and government portals, which help to inform citizens of retirement age in time.

3. The positive attitude towards elderly citizens and the positive attitude towards older citizens who decide to study for continuing their development regardless of age that have been formed in society. 
4. The state must apply the appropriate mechanisms of public administration: legal, organizational and social in order for educational services to become available to older citizens.

The very concept of "public management mechanisms" is relatively new in management, including public management. Therefore, the article offers author's definitions [3]. The legal mechanism of public administration is defined as a set of regulated methods or techniques carried out by authorities and organizations through the use of normative legal acts and algorithms such as mandatory actions. According to the authors of the article, the organizational mechanism is the application of a set of state programs and strategies, as well as the creation and functioning of organizational and management structures, which functions include administration, including the provision of services. The social mechanism of public administration is the actions of citizens, public administration bodies, and various types of organizations aimed at forming new ideas in society, and rejecting existing stereotypes in a particular sphere. Only a comprehensive application of such mechanisms can ensure the availability of vocational training and additional vocational education for citizens at the retirement age in different countries. Despite the many differences between European countries and Russia, there are common characteristics in terms of ensuring the availability of vocational training and additional vocational education for citizens at the retirement age.

\section{DISCUSSION}

We consider how the mechanisms of public administration are applied and the availability of educational services abroad and in Russia for citizens of retirement age is ensured. Over the last twenty years, many international treaties and international legal acts have been adopted; the application of them makes it possible to make educational services available to older citizens. Thus, the International Plan of Action on Ageing (hereinafter: the international plan) defines the goal: the provision of guarantees in the economic and social security of elderly citizens by the state. The objectives of the plan are aimed at increasing the capacity of countries to face specific problems effectively related to population ageing and meeting their needs, including educational ones. The international plan also aims to encourage countries to develop public policies and programs of a socio-economic cause aimed at ensuring the social and economic security of elderly citizens, as well as providing them opportunities for self-development. The principles of the international plan are expected to be reflected in national legislation. This study reveals only a few of the recommendations. For example, the recommendation to develop and implement policies on ageing based on specific national needs and goals, which is the principle right and responsibility of each state. Furthermore, there is a recommendation to recognize aging as a gradual and individual process that does not depend on the legal age limits for retirement. These include the recommendation to recognize the readiness of a person for retirement as a process that takes place throughout his or her adult life. That is why individuals themselves, as well as institutions such as universities, schools, industrial work centers, the media and society as a whole, play a significant role in this process. An important recommendation is to recognize the right of older citizens to continue working in satisfactory conditions, job security, training and retraining. To do this, states are encouraged to develop educational programs that would meet the educational needs of older citizens allowing them to prepare for the period of aging and continued employment [4].

The text of the European Social Charter includes a provision that ensures the right of an elderly person to vocational training. The laws of European countries that have ratified international treaties and legal acts reflect all the provisions on access to education for older citizens. For example, in Germany the right to education of people of all ages is enshrined in the country's Constitution, and the specification of this rule of law is presented in the Federal law "On the promotion of education" ("Bundesausbuldungforderungsgesetz") [5]. The main document defining the state policy of the Czech Republic in the field of education was the "people's program for the development of education in the Czech Republic (White book)", adopted on February 7, 2001. This document defines the goals of education and training, strategic directions of educational policy, principles of management and financing, international cooperation in education, development of different levels of education, including professional education for adults [6].

In Russia the main law is the Constitution, it contains rules that enshrine the rights of citizens regardless of age. There is no provision in the Russian Constitution for the priority protection of the rights of elderly, but generally the Russian state has undertaken to comply with the norms contained in international legal acts. Thus, the Federal law "On education in the Russian Federation" establishes that citizens of the older generation have the right to be included in the educational process. The same law for the first time fixed the concept of 'continuous education', which provides for the possibility of realizing the right of citizens to education throughout their life [7]. Changes are being made to industry laws, for example, in accordance with the law "On employment in the Russian Federation". Regional employment agencies are allowed to send citizens of retirement age for vocational training and additional vocational education if they want to resume working in the professions in demand on the labor market after the official registration of a pension [8].

The Russian Federation also adopted Federal law No. 350FZ "On amendments to certain legislative acts of the Russian Federation for the appointment and payment of pensions". This law establishes a gradual increase of the retirement age in Russia from 55 to 60 for women and from 60 to 65 for men, as well as rules that guarantee benefits to citizens of preretirement and retirement age including training [9].

The study of the text of the Strategy for action in the interests of older citizens in the Russian Federation until 2025 gives an idea of what rights are supposed to be provided. The text of the Strategy presents the characteristics of older citizens as carriers of knowledge and experience. It is recognized that they make a significant contribution to the total intellectual potential of the country, strive for 
In the Russian Federation, as in other European countries, employment, create a significant part of material goods and actively participate in the processes of social development [10]. The text of the Strategy provides for specific directions and priorities, as well as conditions that should be created in the state through the integrated application of public administration mechanisms. There is such a direction as ensuring the guarantee of income for citizens of the older generation by stimulating employment using their educational and labor potential. To implement this direction, it is planned to create conditions for training older citizens, to adapt the content of additional professional education programs to the needs of both citizens and employers. It is considered to overcome negative stereotypes about old age, discrimination against older people, as well as to create a favorable environment that will promote active longevity and integration of older citizens into society.

Such document as the Resolution of the Government of the Russian Federation of January 25, 2019 No. 35 is of interest. The text of this document reflects the Russian and foreign experience in the complex application of public administration mechanisms used for the development of the educational potential of elderly citizens. This act establishes the rules for granting subsidies from the Federal Budget to non-profit organizations for vocational training and additional vocational education of people at the pre-retirement age. The document provides that the recipient of subsidies should be a non-profit organization established in the organizational and legal form of the "Union". The purpose of this organization is to develop professional education in accordance with WorldSkills standards, as well as to provide the Russian economy with highly qualified personnel [11].

Therefore, the provision of additional professional education services for older citizens should be carried out in promising and popular professions. According to the authors of the article, the implementation of this task increases the success for employment and continued employment. Every year the Russian state plans to send 25 thousand of citizens to receive vocational training and additional vocational education.

It is also important for non-profit organizations receiving subsidies for financial support of expenses for educational services during 2019-2024. This condition is in line with the recommendations of the international plan of action on ageing.

The requirements that are mandatory for the implementation of vocational training and additional vocational education programs are commendable. First, it is the preparation of individual recommendations to people at the pre-retirement age in accordance with their professional competence. Secondly, it is an opportunity to use the distance form for training. These requirements are in line with the recommendations of the international plan of action on ageing. Foreign researchers Van Dalen, P. Hendrik, K. Henkens, J. Schippers share the same view: they believe that long-term employment of older workers requires such conditions as an individual approach to decision-making on termination or continuation of employment, as well as the opportunity for professional retraining [12]. conditions for obtaining additional vocational education and scholarships are provided by state employment centers. They give directions, but only if the period from the moment of dismissal of the citizen does not exceed 12 months [9]. But this condition is more stringent in terms than in other countries. The most important organizational condition for the availability of additional professional education services is to inform the elderly. In Russia, since the introduction of the pension reform, the informational and legal portal "PrePensioners" has been operating. This portal provides access to regulatory legal acts, information on benefits and allowances, and provides an opportunity to get answers to questions. Today on the regional websites of the employment departments there is a section "University of the third age". There is an example of the content of the Interactive portal of The Department of Labor and Employment of the Sverdlovsk region. There is a bank of educational programs that are recommended for the organization of vocational training, a list of the most popular professions (specialties) in the labor market of the Sverdlovsk region for training citizens of preretirement age in the direction of the employment service. The forms offered to citizens of pre-retirement age are: retraining, advanced training in the professions of workers and positions of employees, professional retraining and advanced training. In this case, the requirement is that citizens have a basic secondary (including primary) vocational education or higher education. The list of specialties of additional professional education is extensive: from architecture, design, administrative and office activities to electricity and law [13].

The existence of laws and other regulations allows public authorities in different countries to 'launch' the organizational mechanism. The result of the application of the organizational mechanism is the provision of educational services to elderly citizens, which are financed from the state budget. This condition maximizes the availability of educational services for older citizens. Most employers, no matter what state they live in, do not want to invest in the professional development of older workers. This opinion is shared by foreign researchers. For example, M. Fleischmann and F. Koster believe that employers are ready to train employees throughout their careers if the state compensates their expenses [14].

Also, researchers justify the need for such conditions as advanced training of older workers at work. A. Fejes analyzes the positive experience of Sweden, where conditions for the training of older citizens, including in the health sector have been created in recent decades [15]. In the Netherlands, many educational organizations cooperate with enterprises and organizations in the service sector to implement the project "Pension in the long term" [16].

The use of the organizational mechanism involves not only creating conditions for the provision of services to older citizens, but also ensuring quality. At the same time, the main criterion for the quality of educational services that older citizens receive is the possibility of their subsequent employment. German researchers H.P. Tews, W.K. Schreiber, J. Schott analyze the results of the Heidelberg Center for professional retraining; they compare it with the results of 
other centers. They conclude that over the past 20 years, graduates of this center have a higher level of professional integration in the labor market. One of the reasons for the success of graduates, according to these authors, is the quality of vocational training, which reaches the level of training in universities of applied sciences. For example, as it is in the University of Hamburg, where the age of students is not limited, and the quality of education is ensured by a large amount of time devoted to practical and laboratory classes. Accordingly, the level of professional qualifications of graduates of the Heidelberg Center corresponds to the "Fachschule" or "qualified technician" and $10 \%$ of employment, and the level of professional qualification "Fachhochschule" or University graduate of applied sciences is $10 \%$ [17].

According to the researchers, the next condition, which ensures the quality of education of elderly citizens and their subsequent employment, is the use of specific educational methods. P. Jarvis analyzes the application of techniques that are provided by such a direction of education as gerontology of education, it is commonly known as "learning in later years". In his opinion, these methods and the direction have become particularly popular in many European countries, since the share of older people in the population structure reaches a critical level [18]. The authors of this article believe that it is useful to use the existing professional knowledge and skills of 'adult students' when teaching elderly citizens, as well as to provide an opportunity to evaluate life and professional experience from the present time. It is also advisable to integrate older people into groups of students of different ages, which creates a synergistic effect when interacting in group tasks and sharing experiences.

International experience is being actively studied and adapted in Russia. One of these borrowings is the planning of professional skill championships for older workers called "Skills of the Wise" (WorldSkills). According to the authors of this article, such competitions are another condition for motivating citizens at the age over 50 years to study. A mandatory condition for the availability of vocational training and additional professional education for citizens at the retirement age, both in Russia and abroad, is along with the regulatory legal and organizational mechanisms, the use of a social mechanism. An interesting and little-known field is the study of the concept of "successful aging", which began to be used in different national cultures. M. Tam, R. Aird, G. Boulton-Lewis, and L. Buys have presented the results of a study aimed at understanding what successful aging and subsequent learning mean for older people from two different cultures (Hong Kong and Australia). They have found that there are more similarities than differences between older people in Hong Kong and Australia in understanding the meaning of aging and learning, and in justifying reasons for retraining [19]. That is why it is important to conduct crosscultural comparative studies to identify both cultural differences and similarities between cultures.

The concept of "successful aging" is updated in the concept with the same name. The authors of the concept develop ideas about how aging should best proceed, using modern advances in medicine and gerontology. According to the concept, older people who "age successfully" make known efforts to maintain brain activity, continuously learning and expanding social contacts with people of the younger age group. And one of the most important motives is the desire to remain competitive professionally [20]. This concept is beginning to be promoted in Russia, which, according to Russian Researchers G. Zborovsky and P. Ambarova, means the beginning of a new type of behavioral strategies that develop in different age communities, based on overcoming the boundaries and barriers prescribed by age in a diverse range of activities and interaction [21].

\section{CONCLUSION}

Despite the continuing economic and social differences, Russia and many European countries are experiencing similar processes including the creation of conditions for ensuring the availability of vocational training and additional vocational education for citizens at the retirement age. First of all, the mechanisms of public administration that are used by governments of different countries to ensure the availability of educational services for citizens at the retirement age are similar. In many ways, the behavior of employers who are not particularly ready to invest in educational services for older workers is similar, so the state takes the cost of training completely on itself or compensates some of the costs to employers. In many ways, the behavior of citizens of retirement age is similar: each of them makes a decision about professional retraining or professional development, based on their individual decision to continue or to stop working, respectively, their decision to study. It is common for many countries to develop such areas as gerontology education or "learning in later years". Humanity is slowly moving towards the realization of new values and opportunities for the elderly.

\section{Acknowledgment}

We thank the administration of Institute of Economics and Management, Ural Federal University named after first President of Russia B. N. Yeltsin for support of the internal grant "Mechanisms of public administration human capital development for elderly citizens", as well as for adopting the ideas of the teachers.

\section{References}

[1] Hamburg Declaration on Adult Education: [Adopted by the Fifth International Conference on Adult Education, Hamburg, Germany, 1418 July 1997]

[2] T. M. Kononygina, "Management of gerontology: formation, functioning, prospects", the candidate dissertation for Social Sciences. Orel: 2004, 18p.

[3] L. Voronina, T. Rezer, "Application of public administration mechanisms for the development of the educational potential of elderly citizens in the foreign and Russian experience", [Proceeding of Edulearn 19 Conference 1st-3rd July 2019, Palma, Spain, p. 4265, 2019].

[4] "Madrid international plan for action on ageing 2002", [Resolution of the Second World Assembly on Ageing, Madrid, 8-12 April, 2002].

[5] E. S. Kononygina, "System of education management in Germany", NB: Administrative law and practice of administration, Moscow, vol. 7, pp. 100-136, 2013. 
[13] "University of the third age", Interactive portal of the Department of Labor and Employment of the Sverdlovsk region, 2019.

[14] M. Fleischmann, F. Koster, "Older workers and employer-provided training in the Netherlands: A vignette study", Aging and Society, Cambridge University Press, 38(10), p. 1995-2018, 2018.

[15] A. Fejes, "Discourses on employment: Establishing the responsible citizen”, Studies in Continuing Education, 32 (2), pp. 89-102, Sweden, 2010

[16] "Continuous education and the need for it", Moscow, Nauka, p. 164, 2005.

[17] P.H. Tews, W.K. Schreiber, J. Schott, "Vocational rehabilitation in German vocational retraining centres and results of Berufsförderungswerk" Heidelberg gGmbH | [Berufliche rehabilitation in Berufsförderungswerken und ergebnisse der Berufsförderungswerk Heidelberg gGmbH]. Rehabilitation, Stuttgart, 2003, 42 (1), pp. 36-44.

[18] P. Jarvis, "Learning in later life. An Introduction to Educators and Careers”. London: 2001.162 p.

[19] M. Tam, R. Aird, G. Boulton-Lewis, L. Buys, "Aging and learning as conceptualized by senior adults in two cultures: Hong Kong and Australia", Current Aging Science, 9 (3), pp.162-177, 2016.

[20] J. D. Rowe, R. L Kahn, "Successful aging", The Gerontologist, no. 4, vol. 37, pp.433-440, 1997.

[21] G. Zborovsky, P. Ambarova, "Temporal contradictions of communities", Sociological Journal, vol. 23, No. 2, pp. 8-27.

[12] V. Dalen, P. Hendrik, K. Henkens, J. Schippers, "Productivity of older workers: Perceptions of Employers and Employees", Population and development review, SAGE Publications, vol. 36. No. 2, p. 309, 2010, June. 